\title{
Quantitative Estimation of Asiatic acid, Asiaticoside \& Madecassoside in two accessions of Centella asiatica (L) Urban for Morpho-chemotypic variation
}

\author{
Abhishek Gupta, Shikhar Verma, Pradeep Kushwaha, Sharad Srivastava* and AKS Rawat \\ Pharmacognosy \& Ethnopharmacology Division, CSIR-National Botanical Research Institute, Lucknow-226001, Centella asiatica (L) \\ Urban
}

\begin{abstract}
Aim and Scope: Two morphologically distinct accessions of Centella asiatica (SL and LL) from Indo-Gangetic plains of India were compared in relation to the levels of triterpenoid saponins. The plant was evaluated through its morphology, quantitative microscopy and physico-chemical tests. Materials and Methods: The metabolites madecassoside, asiaticoside and its sapogenin asiatic acid were analyzed and quantified by HPTLC. A comparison and evaluation of different parameters together with triterpenoid content in these morphotypes are reported. Results: Quantitative microscopical studies doesn't show any significant difference except in terms of stomatal number, which was found to be higher in LL. Total sugar, starch, tannins and phenols doesn't showed any significant variation in both accessions. Concentration of asiatic acid, asiaticoside and made cassoside found in SL accession were 0.04\%, 0.34\% and 0.38\% respectively, while in LL it was $0.05 \%, 0.31 \%$ and $0.31 \%$ respectively. Thus, showing closely similar quantity of metabolites in both the morphotypes. Conclusion: It can be concluded that the leaf size is not a deciding factor for the concentration of secondary metabolites present in a plant. Reported data will contribute to the establishment of knowledge about the triterpenoidal saponin composition of different morphotypes of C. asiatica found in Indo-Gangetic plains of India and lays a foundation for future studies on Chemotypic variations.
\end{abstract}

Keywords: Asiatic acid, asiaticoside, madecassoside, C. asiatica, chemotype, morphotype.

\section{INTRODUCTION}

Centella asiatica (L) Urban (Apiaceae) is claimed to possess various healing effects and antioxidant properties. It has been reported to be used in the treatment of asthma, ulcers, lepsory, vein diseases, ${ }^{1}$ memory improvement, ${ }^{2}$ antidepressant, ${ }^{3}$ antibacterial, antifungal, ${ }^{4}$ psoriasis. ${ }^{5}$ The medicinal values of this plant are mainly attributed to the presence of triterpenes like asiatic acid, madecassic acid, asiaticoside and madecassoside. ${ }^{6}$ Triterpenes being the major components of $C$. asiatica, they have been regarded as its biomarker components. ${ }^{7}$ Quantification of triterpenes of $C$. asiatica has been successfully established by several researchers using HPLC-UV ${ }^{8-10}$ and HPTLC ${ }^{11}$ however, the triterpene components in C. asiatica are known to vary depending on its growth, location and the diverse environmental conditions. ${ }^{12}$ Analytical studies have shown that C. asiatica contains triterpenoids, essential oils and amino acids. The plant contains asiaticoside, centelloside, madecassoside, brahmoside, brahminoside, thankuniside, centellose and terminolic, asiatic, brahmic, centic, centoic, centellic and madecassic acids. ${ }^{13}$ A study on C. asiatica found that out of two accessions that were evaluated, the accession with larger leaf contained higher amount of triterpenoids. ${ }^{14}$ This study was done to check the chemotypic variations of active biomarkers in correlation with morphotypic changes in C. asiatica collected from Indo-Gangetic plains of India.
DOI: $10.5530 /$ ijper.48.3.9

Address for correspondence: Dr. Sharad Srivastava Pharmacognosy \& Ethnopharmacology Division, CSIR-National Botanical Research Institute, Lucknow-226001

Phone: 0522297816

Fax: +91522-2207219, 2205839

E-mail: pharmacognosy1@ rediffmail.com

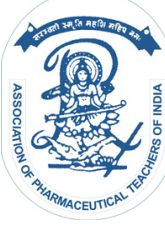

www.ijper.org 


\section{MATERIALS AND METHODS}

\section{Chemicals}

Standard asiatic acid, asiaticoside and madecassoside was procured from Sigma-Aldrich (Steinheim). All other chemicals used were from Merck (Germany).

\section{Plant Materials}

Whole plants of $C$. asiatica were collected from two locations of Varanasi, India in 2011 and authenticated by Dr. AKS Rawat, NBRI, Lucknow. Voucher specimen $(262541 ; 262542)$ has been submitted in institute's repository.

\section{Quantitative Microscopical Studies}

The leaf microscopic characters like stomatal number, stomatal index, vein islet number and vein termination number were determined. The quantitative determination of some pharmacognostic parameters is useful for setting standards for crude drugs. The vein termination, vein islet, stomatal number and stomatal index parameters determined in the quantitative microscopy, are relatively constant for plants and can be used to differentiate closely related species. ${ }^{15}$

\section{Physicochemical and Phytochemical Studies}

Physicochemical and phytochemical studies viz. extractive values, total ash, acid insoluble ash, total sugar, starch, tannin and phenols were estimated from shadedried and powdered plant material. ${ }^{16-18}$

\section{Preparation of Plant Extracts}

Fresh plant material was thoroughly washed with water to remove all debris and then shade dried; the dried material was then powdered using electric grinder at 100 mesh size. Extraction was performed by soxhlation process in two steps. Firstly the powdered material was defatted under soxhlet assembly using $250 \mathrm{~mL}$ of $98 \%$ ether for 6 hours. This is followed by 9 hours soxhlation of defatted powder by using $250 \mathrm{~mL}$ of methanol as solvent. The final extracts were passed through Whatman No. 1 filter paper. The filtrates obtained were concentrated under vacuum in a rotary evaporator at $40{ }^{\circ} \mathrm{C}$ and stored at $4{ }^{\circ} \mathrm{C}$ for further use.

\section{HPTLC Studies}

Extract as prepared above were redissolved in methanol, filtered and finally made up to $100 \mathrm{ml}$ with methanol prior to HPTLC analysis.

\section{Chromatographic Conditions}

Chromatography was performed on Merck HPTLC precoated silica gel $60 \mathrm{GF}_{254}(10 \mathrm{X} 10 \mathrm{~cm})$ plates. Methanolic solution of samples and standard compounds asiatic acid, asiaticoside and madecassoside of known concentrations were applied to the layers as $6 \mathrm{~mm}$-wide bands positioned $10 \mathrm{~mm}$ from the bottom and $15 \mathrm{~mm}$ from side of the plate, using Camag Linomat $\mathrm{V}$ automated TLC applicator with nitrogen flow providing a delivery speed of $150 \mathrm{nl} / \mathrm{s}$ from application syringe. These conditions were kept constant throughout the analysis of samples. Following sample application, layers were developed in a Camag twin trough glass chamber which was pre-saturated with mobile phase of toluene: ethyl acetate: formic acid (5:5:1) for asiatic acid and n-butanol: ethyl acetate: water (4:1:5) for asiaticoside and madecassoside till proper separation of bands up to $8 \mathrm{~cm}$ height. After development, layers were dried with an air dryer. Asiatic acid, asiaticoside and madecassoside were simultaneously quantified using Camag TLC scanner model 3 equipped with Camag Wincats IV software. Following scan conditions were applied: slit width, $6 \mathrm{~mm} \times 0.45$ $\mathrm{mm}$; wavelength $600 \mathrm{~nm}$; and absorption-reflection mode. In order to prepare calibration curves, stock solution of asiatic acid, asiaticoside and madecassoside (0.1 $\mathrm{mg} / \mathrm{ml}$ ) was prepared and various volumes of the solution were analyzed through HPTLC, calibration curves of peak area vs. concentration were also prepared.

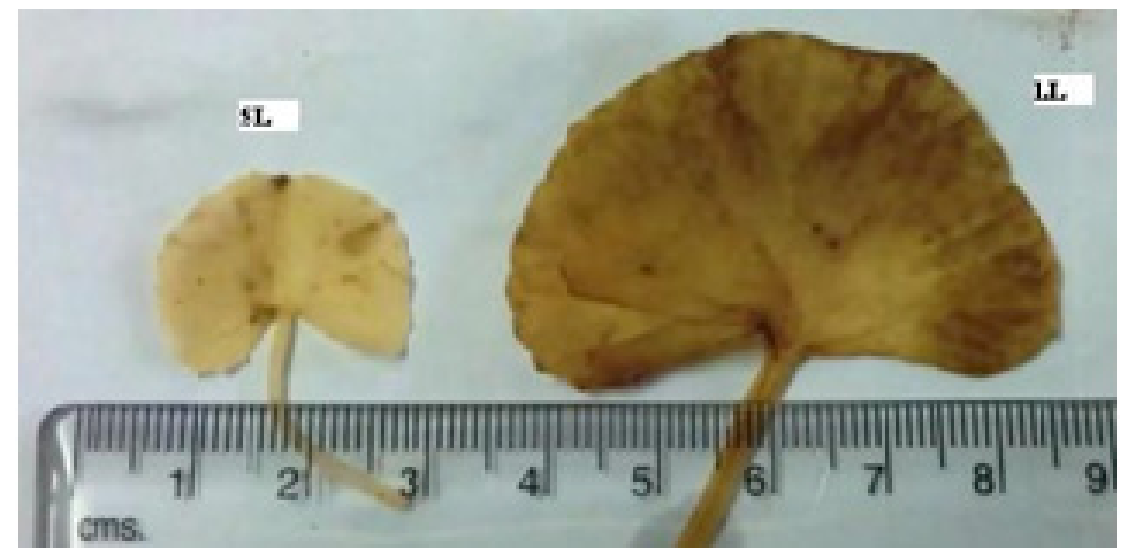

Figure 1: Accessions of C. asiatica Leaf (SL \& LL) 


\section{RESULTS AND DISCUSSION}

\section{Quantitative Microscopical Studies}

Stomatal number, stomatal index, vein-islet and vein termination number was determined and results are shown in Table 1.

\section{Physicochemical Studies}

Parameters such as extractive values (Water and alcohol soluble), total ash, acid insoluble ash, total sugar, starch, tannins and phenolics were determined and results are shown in Figure 2.

\begin{tabular}{lllllll}
\multicolumn{6}{l}{ Table 1: Quantitative microscopical parameters of C. asiatica accessions } \\
Accession & V.T & V.I & S.I (lower) & S.I (upper) & S.N (lower) & S.N (upper) \\
\hline SL & $3.0-7.0$ & $2.0-5.0$ & $18.81-20.16$ & $8.0-11.0$ & $100-175$ & $50-75$ \\
LL & $4.0-8.0$ & $2.0-6.0$ & $19.96-22.45$ & $9.0-11.0$ & $125-225$ & $75-100$ \\
\hline
\end{tabular}

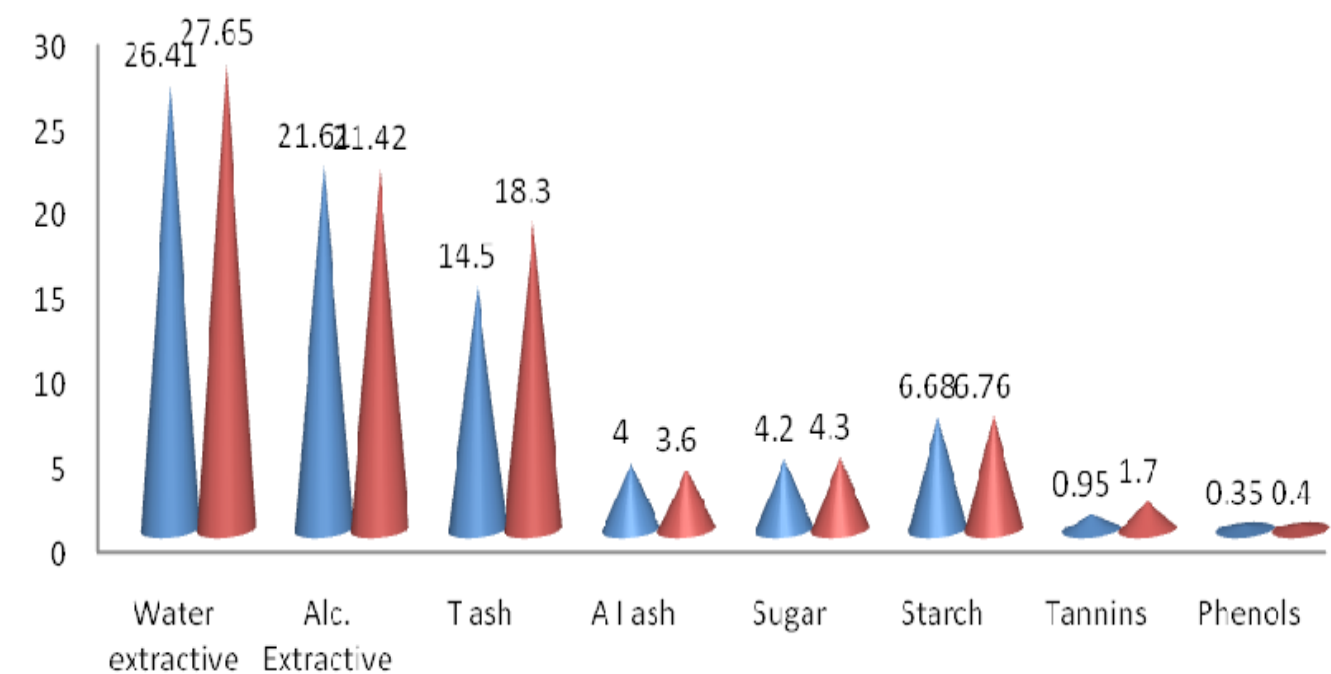

$\square \mathrm{SL} \nabla \mathrm{LL}$

Figure 2: Physicochemical parameters of $C$. asiatica

\section{HPTLC Studies}

The calibration plots were obtained after densitometric analysis of the three authentic standards i.e., asiatic acid, asiaticoside and madecassoside. Chromatographic details are shown in Table 2. Quantification of asiatic acid, asiaticoside and madecassoside in the samples of C. asiatica has been performed and shown in Table 3 . HPTLC banding pattern and densitograms obtained from extracts are shown in Figure 3.

\section{Table 2: Chromatographic details}

\begin{tabular}{cccc} 
Parameters & Asiatic acid & Asiaticocide & Medecassoside \\
\hline Rf & $0.51 \pm 0.005$ & $0.44 \pm 0.01$ & $0.33 \pm 0.01$ \\
Linearity range & $100-1000 \mathrm{ng}$ & $100-1000 \mathrm{ng}$ & $100-1000 \mathrm{ng}$ \\
Regression via area & $y=436.218+6.020^{*} \mathrm{x}$ & $\mathrm{y}=638.777+6.375^{*} \mathrm{x}$ & $\mathrm{y}=164.551+3.504^{*} \mathrm{x}$ \\
$\mathrm{r}$ & 0.999 & 0.992 & 0.998 \\
Slope & 6.020 & 6.375 & 3.504 \\
Intercept & 436.218 & 638.777 & 164.551 \\
LOD & $40 \mathrm{ng}$ & $40 \mathrm{ng}$ & $40 \mathrm{ng}$ \\
LOQ & $100 \mathrm{ng}$ & $100 \mathrm{ng}$ & $100 \mathrm{ng}$
\end{tabular}




\section{Table 3: Concentration of different markers in C. asiatica samples}

\begin{tabular}{ccccc} 
Markers & $\mathbf{R}^{2}$ & $\mathbf{R}_{\mathbf{f}}$ & \multicolumn{2}{c}{ Amount Quantified (\%) in Crude Drug } \\
\hline & & & $\mathbf{S L}$ & LL \\
\cline { 2 - 5 } Aisatic acid & 0.98 & $0.51 \pm 0.004$ & $0.04 \pm 0.00$ & $0.05 \pm 0.01$ \\
Asiaticoside & 0.99 & $0.44 \pm 0.005$ & $0.34 \pm 0.03$ & $0.31 \pm 0.04$ \\
Madecassoside & 0.99 & $0.33 \pm 0.004$ & $0.38 \pm 0.02$ & $0.31 \pm 0.05$ \\
\hline
\end{tabular}

Each percentage value is an average of six values $\pm \mathrm{SD}$

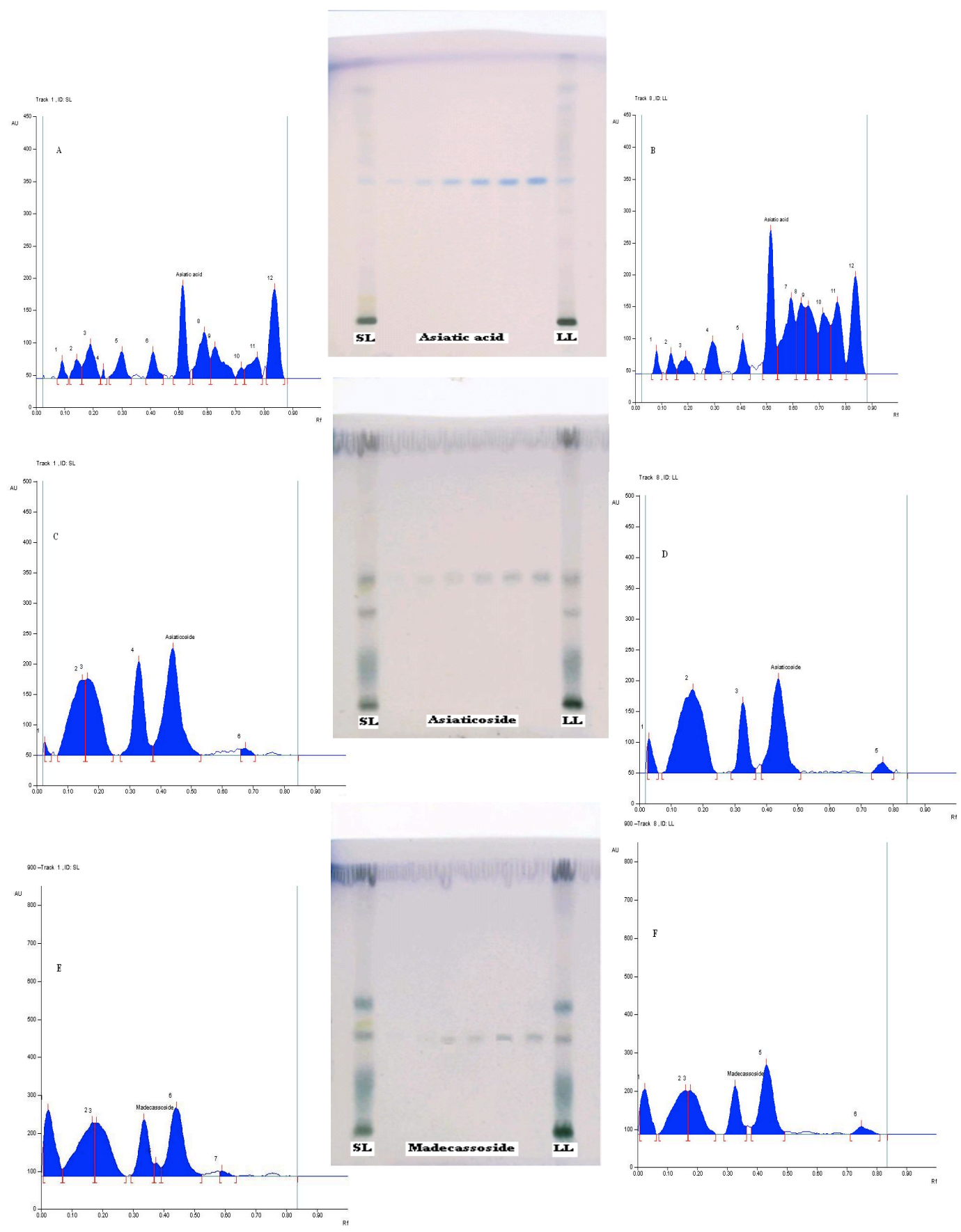

Figure 3: HPTLC Profile and Densitogram showing C. asiatica extracts-SL \& LL with Asiatic acid (A \& B), Asiaticoside (C \& D) and Madecassoside (E \& F) 


\section{CONCLUSION}

There was no marked variation found in botanical descriptors, physicochemical parameters as well as in bioactive metabolites asiatic acid, asiaticoside and madecassoside quantified through HPTLC, this leads to a conclusion that morphotypic variations does not always lead to chemotypic variations in $C$. asiatica. The presence of asiatic acid, asiaticoside and madecassoside quantified in these accessions may be utilized for the proper identification of elite chemotypes of the drug. The concentrations of asiatic acid, asiaticoside and madecassoside showed no significant variation in both accessions. It can be concluded that the leaf size is not a deciding factor for the concentration of secondary metabolites present in a plant. This finding is however different from a similar work published earlier. ${ }^{14}$ This may be due to the different determination methods and parameters used by those workers. Reported data will contribute to the establishment of knowledge about the triterpenoid saponin composition of different morphotypes of C. asiatica found in Indo-Gangetic plains of India and lays a foundation for future studies on chemotypic variations of $C$. asiatica.

\section{ACKNOWLEDGEMENT}

The authors are thankful to Director, CSIR -NBRI for providing all the facilities (under OLP-0077) to conduct this research work, authors are also thankful for financial grant under CSIR-EMPOWER scheme.

\section{CONFLICT OF INTEREST}

The authors declare no conflict of interest

\section{ABBREVIATIONS}

SL: Small Leaf; LL: Large Leaf; S.N: Stomatal Number; S.I: Stomatal Index; V.T: Vein Termination Number; V.I: Vein Islet Number; HPTLC: High Performance Thin Layer Chromatography

\section{REFERENCES}

1. Brinkhaus B, Lindner M, Schuppan D, Hahn EG. Chemical, pharmacological and clinical profile of the East Asian medicinal plant Centella asiatica. Phytomedicine. 2000; 7(5): 427-48.

2. Rao S.B, Chetana M, Uma Devi P. Centella asiatica treatment during postnatal periodenhnaces learning and memory in mice. Physiol. Behav. 2005; 86: 449-57.

3. Chen $Y$, Han T, Rui $Y$, Yin M, Qin L, Zheng H. Effects of total triterpenes of Centella asiatica on the depression behavior and concentration of amino acid in forced swimming mice. Zhong Yao Cai. 2003; 26: 870-73.

4. Ullah MO, Sultana S, Haque A, Tasmin S. Antimicrobial, cytotoxic and antioxidant of Centella asiatica. Eur. J. Sci. Res. 2009; 30(2): 260-4.

5. Sampson JH, Raman A, Karlsen G, Navsaria H, Leigh IM. In-vitro keratinocyte antiproliferation effect of Centella asiatica extract and triterpenoid saponins. Phytomedicine. 2001; 8(3): 230-5.

6. Ling APK, Marziah M ,Tan SE. (eds.) Triterpenoids distribution in whole plant and callus cultures of Centella asiatica accessions. Proceeding of the 16th National Seminar on Natural Products; 24-25 October, 2000; Serdang, Malaysia; 2000.

7. Zheng CJ, Qin LP. Chemical components of Centella asiatica and their bioactives. J. Chin. Integr. Med. 2007; 5(3): 348-51.

8. Inamdar PK, Yeole RD, Ghogare AB, de Souza NJ. Determination of biologically active constituents in Centella asiatica. J. Chromatogr. 1996; 742(1): 127-30.

9. Zainol NA, Voo SC, Sarmidi MR, Aziz RA. Profiling of Centella asiatica (L.) Urban extract. Malaysian J. Anal. Sci. 2008; 12(2): 322-27.

10. Rafamantanana MH, Rozet E, Raoelison GE, Cheuk K, Ratsimamanga SU, Hubert P, Quetin-Leclercq J. An improved HPLC-UV method for the simultaneous quantification of triterpenic glycosides and aglycones in leaves of Centella asiatica (L.) Urb (Apiaceae). J. Chromatogr. B. 2009; 877(23): 2396-402.

11. Jacinda James, Ian Dubery. Identification and Quantification of Triterpenoid Centelloids in Centella asiatica (L.) Urban by Densitometric TLC. Journal of Planar Chromatography. 2011; 1(24): 82-7.

12. James JT and Dubery IA. Pentacyclic triterpenoids from the medicinal herb, Centella asiatica (L.) Urban. Molecules. 2009; 14(10): 3922-41.

13. Jamil SS, Nizami Q, Salam M. Centella asiatica (Linn.) Urban A Review. Natural Product Radiance. 2007; 6(2): 158-70.

14. Zainol NA, Voo SC, Sarmidi MR, Aziz RA. Profiling of Centella asiatica (I.) Urban Extract. The Malaysian Journal of Analytical Sciences. 2008; 12(2): 322-27.

15. Gokhale SB, Kokate CK. Practical Pharmacognosy. $12^{\text {th }}$ ed. Pune: Nirali Prakashan; 2008.

16. Peach K, Tracy MV. Modern Methods of Plant Analysis. Vol III and IV. Heidelberg: Springer; 1955. 258-61.

17. Anonymous. Indian pharmacopoeia. Government of India, Ministry of Health and Family Welfare, New Delhi; 2007.191.

18. Anonymous. Ayurvedic Pharmacopeoeia of India. Government of India. Part I, Vol I. Department of Health, Ministry of Health and Family Welfare, New Delhi; 2004. 152-65. 